\title{
CT-GUIDED PERCUTANEOUS FIXATION OF PELVIC FRACTURES. CASE REPORTS
}

\author{
Jana Chmelováa*, Milan Šír ${ }^{\mathrm{b}}$, Vladimír Ječmínek ${ }^{\mathrm{b}}$ \\ ${ }^{a}$ Radiodiagnostic Institute, University Hospital Ostrava, 70852 Ostrava Czech Republic, \\ ${ }^{b}$ Centre of Traumatology, University Hospital Ostrava, 70852 Ostrava Czech Republic \\ e-mail: jana.chmelova@fnspo.cz
}

Received: April 18, 2005; Accepted (with revisions): June 19, 2005

Key words: Pelvic fracture/Percutaneous fixation/CT-guided surgery

Unstable pelvic fractures are usually associated with high impact energy trauma. As to surgical procedures the most frequently used methods are open reduction and inner fixation (ORIF), the other methods of stabilizing the unstable posterior pelvic ring are percutaneous iliosacral screw fixation under fluoroscopic control and CT-guided percutaneous fixation. The last mentioned procedure eliminates some of the problems associated with surgical treatment: prevents excessive blood loss during manipulation of the fracture hematom, lowers the possibility of infection, allows more accurate screw placement with direct measuring of the screw length and decreases the possibility of nerve injury. The CT-guided fixation is a delicate procedure and its result depends among others on the cooperation between operating room and CT room personnel. The radiologist and CT technologist have to know the operation technique and have to understand surgeon's requirements. In the available literature only a little was written and mentioned about the exact role of radiologist and CT technologist in the team. The aim of this article is to present the operation technique according to authors' own experience with two operated patients and to mention the surgeon's requirements on CT team.

\section{INTRODUCTION}

Unstable pelvic fractures are usually associated with high impact energy trauma and they are being seen with increasing frequency in younger persons. Despite improvement in the management of unstable pelvic fractures, the mortality and morbidity rates remain as high as $10 \%$ and $52 \%$. Non-surgical treatment is mostly disappointing and barely tolerable for the patients (around 45-days traction), results of long-term follow up have shown frequent malunion, late low back and sacral pain and leg length discrepancy. The cause of mortality are mostly: thromboembolic disease, decubital sepsis and multiorgan failure (MOF) ${ }^{1}$. As to surgical procedures the most frequently used methods are open reduction and inner fixation (ORIF). It has been shown that these procedures decrease morbidity as well as mortality; however they cannot be applied in the acute stage of treatment, particular in multiple injuries, with regard to extensive surgical exposure. The most common complications are excessive blood loss and postoperative infection. In addition, the placement of stabilizing sacral screws at surgery is a relatively blinded procedure, guided primarily by palpation, which requires significant expertise $^{2}$. Percutaneous iliosacral screw fixation under fluoroscopic control is another method of stabilizing the unstable posterior pelvic ring ${ }^{3}$. Advantages of this method include minimal invasion of compromised soft tissue, limited blood loss and decreased infection rates. On the other hand, it lacks precision for fracture stabilization in deeper layers. The potential dangers of injury to the $\mathrm{L}_{5}$ nerve root anterior to the sacrum, the $\mathrm{S}_{1}$ nerve in its neural ca- nal and the iliac vessels remain ${ }^{4}$. These shortcomings are overcome by CT-guided percutaneous fixation. It offers the advantage of direct visualization of the course of the screws, increasing accuracy of screw placement and decreasing rate of wound problems. The last mentioned procedure is delicate and requires an experienced surgeon ${ }^{5,6}$. Performed by a well-coordinated team, this miniinvasive method involves stabilization of pelvic ring fractures in the area of SI joints, in non-dislocated fractures and also in the posterior acetabular rim. It enables early rehabilitation and mobilization of the patient and reduces the risk of complications too.

The purpose of this article is to describe the benefits of miniinvasive operation on pelvic structures and to present step by step the operation technique from the radiologist's point of view. The aim is to improve the readiness of the $\mathrm{CT}$ team and to make its cooperation with the surgeons more effective.

\section{CASE REPORTS}

\section{Case 1.}

A 49-year old man was injured in a motor vehicle collision. In addition to unstable posterior ring pelvic fracture he had brain contusion, chest, abdominal and spinal injuries. After pelvic fracture stabilization using skeletal traction, splenectomy and pleural drainage, he was transferred to our ward for pelvic fracture stabilization on day 18 after the accident. 
Plain radiograph of the pelvis demonstrated a fracture of the posterior acetabular rim on the left and left sacral displacement. On day 19 after the accident, the patient was operated on under general anesthesia. He was placed in prone position on the scanning table. Several scans (about ten) were obtained at 5-mm intervals in the region of sacral displacement. From the axial image that

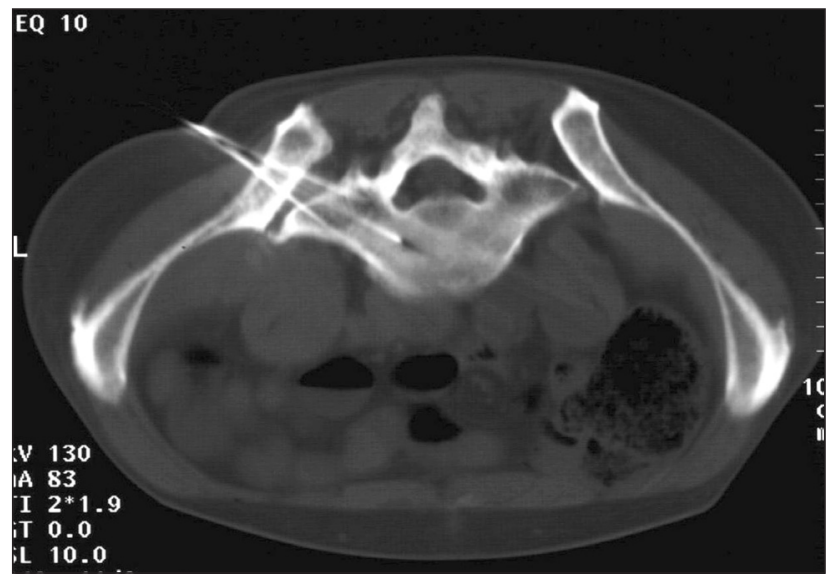

Fig. 1. The axial scan, obtained with the patient prone, demonstrates the placement of three guide pins via posterior part of iliac wing and across SI joint to the mid-body of S-1.

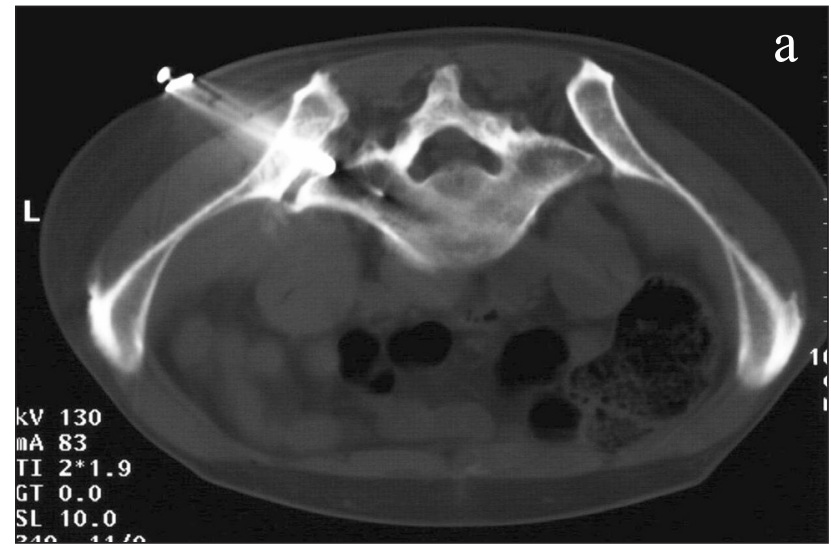

demonstrated the displacement of the SI joint the best, the depth and angle for placement of the guide pin across were determined. The skin entry side was from this image drawn too. Disinfection and draping were done by operating room personnel, all personnel who participated in the procedure were gowned with sterile surgical clothing, except the anesthesiologist and CT technologist. The operator made a small skin incision at the entry side and inserted three guide pins through the iliac wing and across the SI joint to the mid-body of S-1. The position of pins was checked by CT scans (Fig. 1). Cannulated spongious screw $70 \mathrm{~mm} / 16 \mathrm{~mm}$ long with pad was placed along the central guide pin (Fig. 2a). On the scans made, the screw was properly anchored in the sacral bone (Fig. 2b). Subsequently, percutaneous fixation of the posterior acetabular rim fracture was performed using two guide pins inserted under CT-control (Fig. 3). The posterior acetabular rim was fixed with a cannulated screw $80 \mathrm{~mm} / 16 \mathrm{~mm}$ long (Fig. 4). At the end of the procedure, the iliac joint was free to move without any sign of dislocation of the posterior acetabular rims.

The operation team spent a total of 105 minutes in the CT room; the patient spent 55 minutes on the CT table.

The post-operation period was uncomplicated. The operation wounds healed per primam. On day 8 after the operation, the patient was transferred in good condition to the regional hospital; rehabilitation in bed was permit-

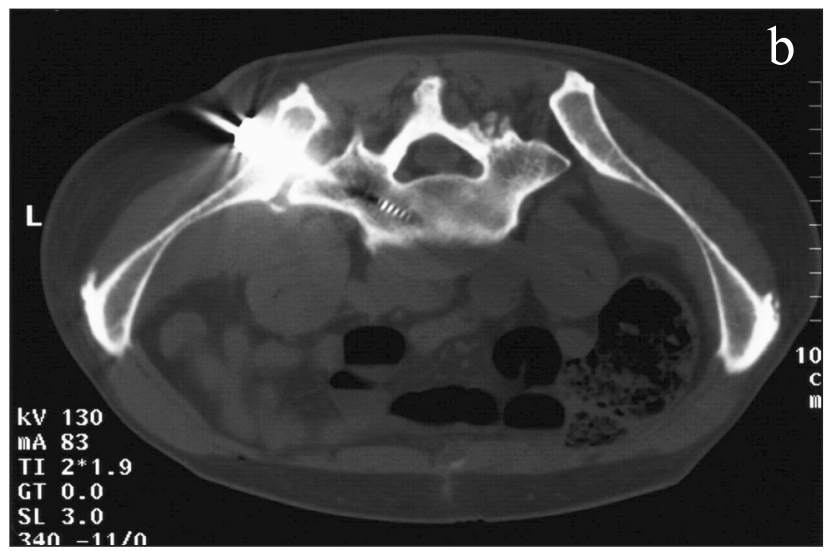

Fig. 2. a) The cannulated screw has been placed along the middle guide pin. b) Final position of the properly anchored screw in sacral bone skeleton.

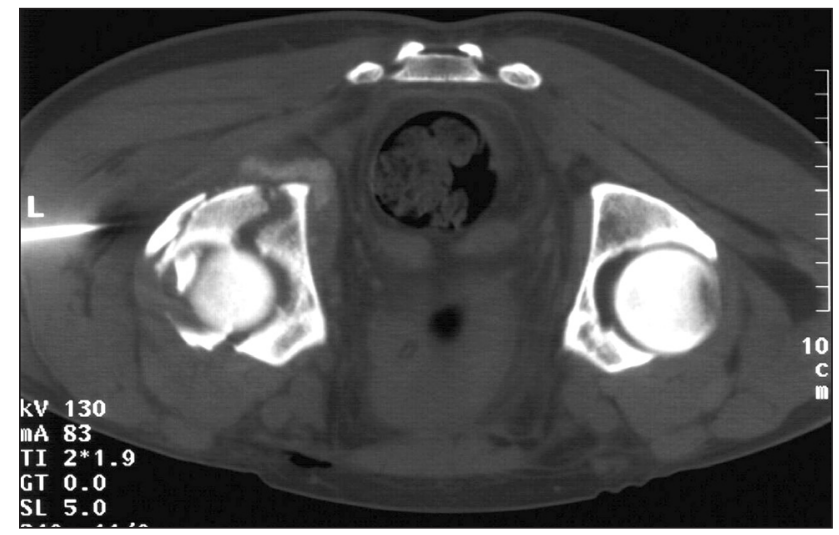

Fig. 3. Percutaneous fixation of the posterior acetabular rim fracture - placement of the guide pin.

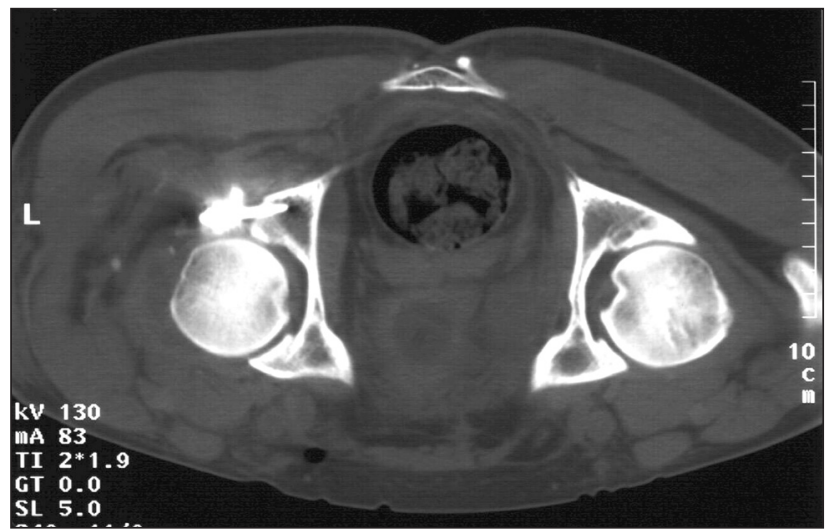

Fig. 4. Fixation of posterior acetabular rim fracture using the cannulated screw. 

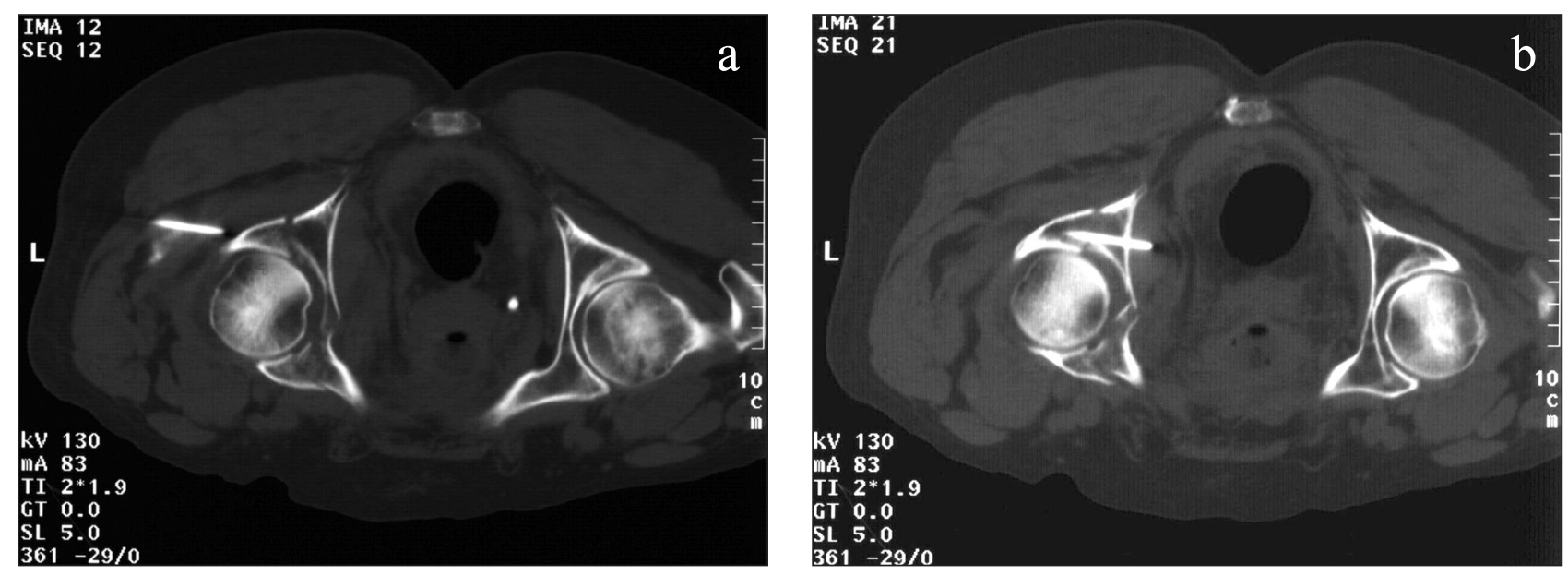

Fig. 5. a) Placement of the guide pin into posterior acetabular rim.

b) Fixation of guide pin into the pillar of iliac bone.
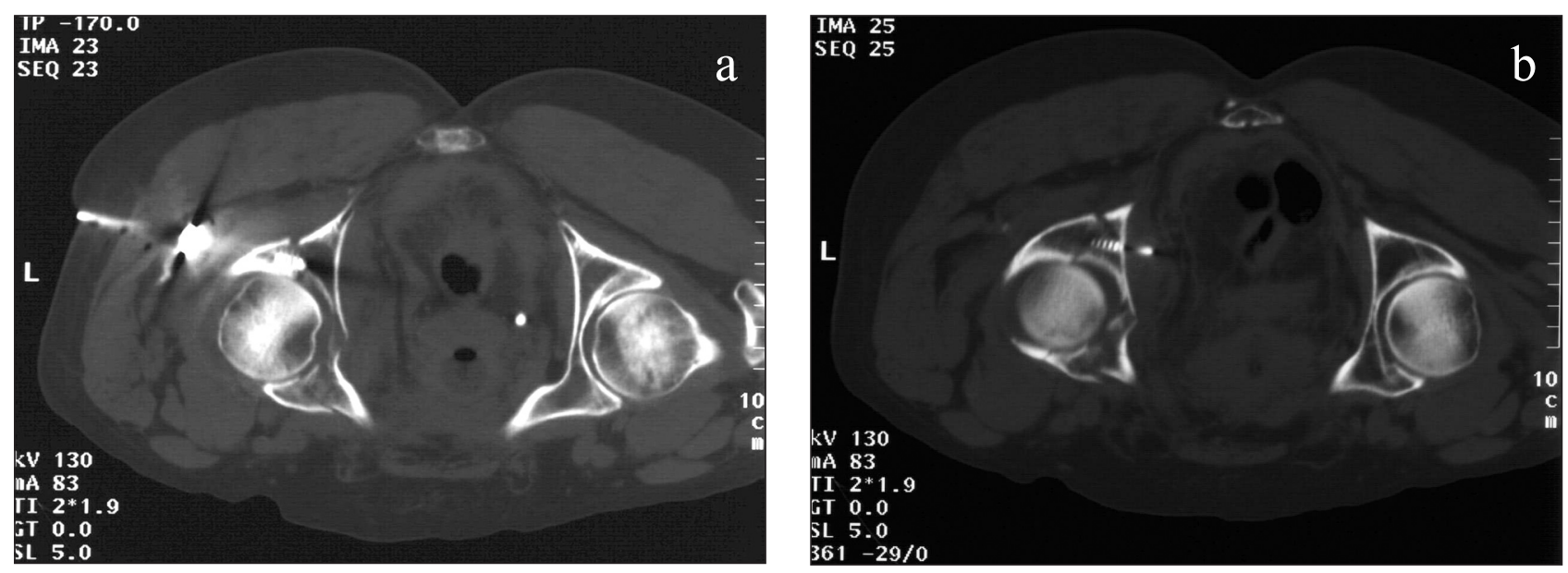

Fig. 6. a) Placement of the cannulated screw along the guide pin.

b) Final position of the cannulated screw on CT scan.

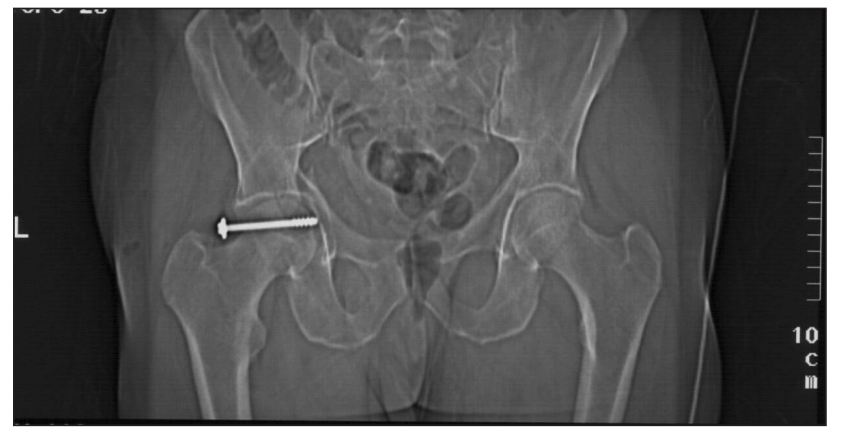

Fig. 7. The topo-scan obtained immediately after fixation shows optimal screw position

ted on day 2 after the operation and standing up and walking without load on the limb was permitted after 4 weeks, with full load on the limb after 3 months. The patient was found to be clinically stable at 1-year follow-up.

\section{Case 2.}

A 59-year old man was knocked-down by a car trailer while riding his bicycle (acetabular fracture on the left). He was transferred to our hospital for osteosynthesis.
Plain radiograph of the pelvis showed fracture of the posterior acetabular rim on the left with dislocation. On the day following the accident, the patient was operated on. He received epidural anesthesia and in prone position he was placed on the scanning table. The surgeon inserted the guide pin into the posterior rim of the acetabulum (Fig. 5a). After reposition, he fixed the pin over the breaking line into the pillar of iliac bone (Fig. 5b). Subsequently, a cannulated screw with pad fixing the fragment of acetabular rim was placed along the guide pin (Fig. 6a,b). The result was checked by $\mathrm{CT}$ scans at 5-mm intervals. On the topo-scan obtained immediately after fixation, the position of the screw was good (Fig. 7). The iliac joint was clinically stable and free to move. The operation team spent a total of 65 minutes in the CT room; and the patient spent 21 minutes on the CT table.

The post-operation period was uncomplicated. The operation wounds healed per primam. On day 3 after the operation, the patient was transferred in good condition to the regional hospital. Rehabilitation in bed was recommended on a moto-splinter on day 2 after the operation, walking without load on the left lower limb in 14 days, with full load after 8 weeks. The patient is clinically stable at 1-year follow-up. 


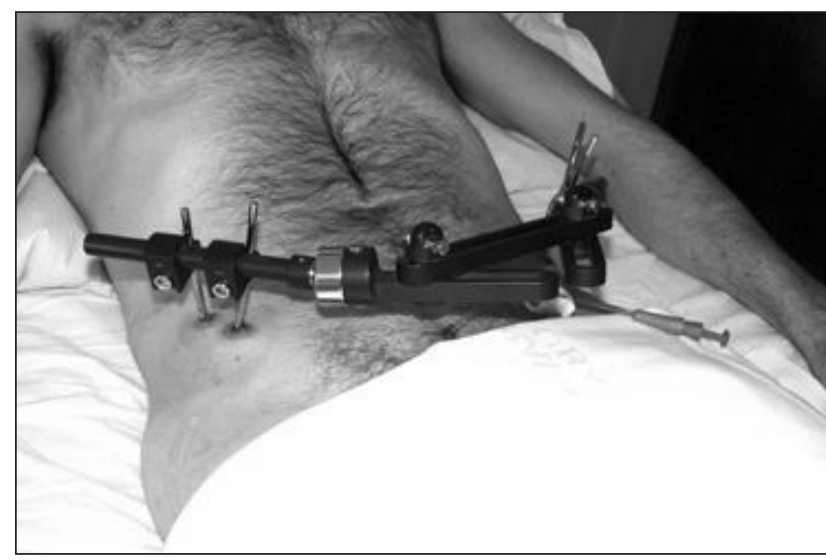

Fig. 8. Type B pelvic fracture stabilised by percutaneous placement of screw into SI joint on the left and stabilisation of symphyseolysis using the external fixator.

\section{DISCUSION}

The first CT-guided sacral fixation was performed by Ebraheim in 1987 (ref. $\left.{ }^{7}\right)$. According to the nowadays literature the most of all long-term experiences with this procedure has Taller's team ${ }^{8,9,10}$. This method eliminates some of the basic problems associated with surgical treatment: prevents excessive blood loss during manipulation of the fracture hematom, obviates manipulation of macerated tissue and thus lowers the possibility of infection ${ }^{11}$. CT control provides direct visualization of the reduced fragments and of the neural foramina and makes possible more accurate screw placement ${ }^{12}$. It decreases the possibility of nerves and pelvic blood vessels injury. Next advantage is the possibility of direct measuring of the screw length and minimal skin scarring, since required skin incision is about $1-2 \mathrm{~cm}$. Further advantage is a rapidity of the procedure. The time which our patients spent in CT room is comparable and even better than the time referred in the literature ${ }^{13,14}$. The rapidity of the procedure partly depends on the type of anesthesia (epidural or general) and the cooperation between operating room personnel and CT technologist.

The operation procedure, however, has to be precisely planned and performed by a medical team including an experienced radiologist and skilled surgeon-traumatologist who both play main roles. The first is a specialist in imaging methods with practice in navigation technology, the second is able to choose quickly and properly the adequate operation procedure, to carry out CT-navigated inner fixation and provide qualified post-operation care. A very demanding situation for the CT staff is the presence of many persons (up to 7) in the CT examination room (who are not used to work with the radiation). As the CT team is responsible for observing the principles of radiation protection, they supervise the others. CT-guided percutaneous fixation of pelvic fractures requires a higher radiation dose than percutaneous fixation under fluoroscopic control does. However, radiation dose

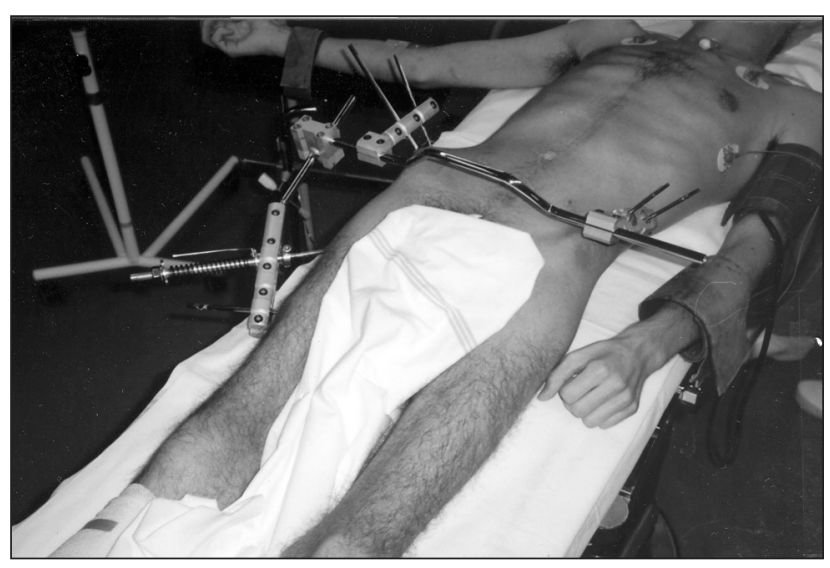

Fig. 9. Type Pennal C pelvic fracture with acetabular fracture fixed by external fixation on pelvis and acetabulum with stabilisation of posterior acetabular rim using the percutaneously guided screw.

can be markedly reduced by optimization of the scanning protocol by changing of anode current. The advantages of computer guided surgery justify CT scans, when based on correctly chosen indications ${ }^{15}$.

CT-guided surgical procedure is not the right procedure for every trauma patient with posterior instability. These interventions are currently indicated predominantly for fractures of the sacrum and for certain types of SI joint displacement (up to $15 \mathrm{~mm}$ distance). Other conditions indicated for CT-guided surgery include simple fractures of the acetabular rim with a distance between the fracture lines up to 7 to $10 \mathrm{~mm}$, usually following hip dislocation, and simple oblique fractures of the acetabular columns. In type $\mathrm{B}$ and $\mathrm{C}$ pelvic ring fractures according to the Pennal classification percutaneous fixation has to be supported by stabilisation of the pelvic ring by external fixation (Fig. 8) including the acetabulum (Fig. 9) $\left(\right.$ ref. $\left.^{16}\right)$. Potential peroperation complications have to be taken into account too. In such an event the immediate conversion to the open method of inner osteosynthesis must be performed.

\section{CONCLUSION}

The CT-guided surgical procedure allows us to assess both the shape and course of fracture lines or distance between the injured structures. It enables to choose the optimal direction for an implant to be inserted and to respect important anatomical structures in the surroundings. Besides this, it helps to determine the exact length of implants to be used.

In conclusion the CT-guided fixation of unstable pelvic ring fractures is a rapid, safe technique with minimal risk of morbidity. It is better to fluoroscopic guidance. It also helps to attain a completely new level with regard to what we can achieve in terms of minimal invasiveness and increased precision. 


\section{REFERENCES}

1. Michek J, Zelníček P, Wendsche P. (2000) Pelvic Compartment Syndrome. Úraz chir. 8, 24-29.

2. Schmucki D, Gebhard F, Grudzner PA, Hufner T, Langlotz F, Zheng G. (2004) Computer aided reduction and imaging. Injury 35, Suppl. 1: S-A96-104.

3. Amiot LP, Lang K, Putzier M, Zippel H, Labelle H. (2000) Comparative Results Between Conventional and Computed-Assisted Pedicle Screw Installation in the Thoracic, Lumbar and Sacral Spine. Spine 25, 606-614.

4. Pleva L, Rozum K, Ječmínek V. (2000) External fixation into acetabulum. Úraz. chir. 8, 1-10.

5. Chmelová J, Pleva L. (2002) Percutaneous Fixation of Pelvic Fractures under CT control. Čes Radiol. 56, 16-20.

6. Jacob AL, Messmer P, Stock KW, Suhm N, Baumann B, Regazzoni P, Steinbrich W. (1997) Posterior Pelvic Ring Fractures: Closed Reduction and Percutaneous CT-guided Sacroiliac Screw Fixation. Cardiovasc Intervent Radiol 20, 285-294.

7. Ebraheim NA, Rusin JJ, Coombs RJ, Jackson WT, Holiday B (1987) Percutaneous computed-tomography-stabilization of pelvic fracture: preliminary report. J Orthop Trauma 1, 197-204.

8. Beran J, Taller S, Lukáš R, Bubeník J. (2001) Osteosyntheses of SI Articulation and Fractures of the Acetabulum under CT control Čes Radiol. 55, 303-306.
9. Taller S, Lukáš R, Šrám J, Beran J. (2003) One Hundred CT guided Operations of the Pelvis. Acta chir orthop Traumatol Cech 70, 279-284.

10. Taller S, Lukáš R, Šram J, Krrivohlávek M. (2005) Urgent management of the complex pelvic fractures. Rozhl. Chir. 84 (2), 83-7.

11. Tonetti J, Carrat L, Lavalleé S, Pittet L, Merloz P, Chirossel JP. (1998) Percutaneous Iliosacral Screw Placement Using Image Guided techniques. Clin Orthop 354, 103-110.

12. Sen M, Harvey EJ, Steinitz D, Guy P, Reindl, R. (2005) Anatomical risks of using supra-acetabular screws in percutaneous internal fixation of the acetabulum and pelvis. Am J Orthop. 34 (2), 94-6.

13. Nelson DW, Duwelius PJ. (1991) CT-guided Fixation of Sacral Fractures and Sacroiliac Joint Disruptions. Radiology 180, $527-$ 532.

14. Shuler TE, Boone DC, Gruen GS, Peitzmann AB. (1995) Percutaneous Iliosacral Screw Fixation: Early Treatment for Unstable Posterior Pelvic Ring Disruptions. J. Trauma 38, 453-458.

15. Slomczykowski M, Roberto M, Schneegerger P, Ozdoba C, Vock P. (1999) Radiation dose for pedicle screw insertion. Fluoroscopic method versus computer-assisted surgery. Spine 24, 975-982.

16. Šimko M. (1998) Fractures of the Acetabulum. Bratislava: Slovak Academic Press. P. 142. 